\title{
Estimating natural and fishing mortality and tag reporting rate of southern rock lobster (Jasus edwardsii) from a multiyear tagging model
}

\author{
S.D. Frusher and J.M. Hoenig
}

\begin{abstract}
Fishing and natural mortality rates and tag reporting rate for rock lobsters (Jasus edwardsii) in northwest Tasmania, Australia, were estimated using multiyear tagging models. These estimates are necessary for assessment of the resource. Several models were examined that had either two or three tagging events each year, and either combined sexes or kept sexes separate. The model that best described the dynamics of the fishery utilized three tagging events within a year. The year was divided into discrete periods and, within each year, fishing effort and duration of period were used to apportion fishing and natural mortalities, respectively, to the periods. The separation of fishing mortalities by sex was not found to improve the models. Although high $\left(1.0-1.2 \cdot\right.$ year $\left.^{-1}\right)$, the instantaneous fishing mortality estimates were comparable to estimates obtained from other methods and the relative standard errors were low. Reporting rate estimates were also precise and indicated a lack of participation by the fishing industry. Estimates of natural mortality were low $\left(0.00-0.02 \cdot\right.$ year $\left.^{-1}\right)$ but imprecise.

Résumé : Les taux de mortalité naturelle et de mortalité due à la pêche ainsi que les taux de signalisation des étiquettes chez la langouste Jasus edwardsii dans le nord-ouest de la Tasmanie en Australie ont pu être estimés à l'aide de modèles pluri-annuels de marquage. Ces estimations sont nécessaires pour l'évaluation de la ressource. Plusieurs modèles ont été examinés qui comportaient deux ou trois sessions de marquage chaque année et qui combinaient ou séparaient les sexes. Le modèle qui décrit le mieux la dynamique de cette pêche commerciale utilise trois sessions de marquage dans l'année. L'année est divisée en périodes distinctes et, au cours de chaque année, l'intensité de la pêche et la durée de la période servent à répartir la mortalité naturelle et la mortalité due à la pêche dans les périodes. La répartition des mortalités dues à la pêche entre les sexes n'améliore pas les modèles. Bien qu'élevées $\left(1,0-1,2 \cdot\right.$ année $\left.^{-1}\right)$, les estimations des taux instantanés de mortalité due à la pêche se comparent aux taux obtenus par d'autres méthodes et les erreurs types relatives sont peu importantes. Les taux de signalisation sont aussi précis et démontrent un manque de coopération de la part de l'industrie de la pêche. Les estimations de la mortalité naturelle sont basses $\left(0,00-0,002 \cdot\right.$ année $\left.^{-1}\right)$, mais imprécises.
\end{abstract}

[Traduit par la Rédaction]

\section{Introduction}

Exploitation rates of crustaceans have often been estimated by depletion methods (Delury 1947; Leslie and Davis 1939). Recently, exploitation rates in the Tasmanian rock lobster (Jasus edwardsii) fishery have been estimated by change-inratio and index-removal methods (Frusher et al. 1997, 1998). These methods measure the relative change in abundance or composition, respectively, of the harvestable population over time. Like depletion methods, they require the population to be closed to immigration, emigration, and recruitment (Pollock and Hoenig 1998; Hoenig and Pollock 1998). However, in many fisheries the population is not closed and the methods used to estimate exploitation rate must follow a specified portion of the resource over time.

Tagging studies on lobsters in northern Tasmania have shown that legal-sized lobsters close to the minimum size limit molt twice a year and there is a residual amount of molting occurring throughout the year. As the population is changing throughout the year, a change in legal-sized lobster abundance would relate to recruitment (molting from undersized to legal size) as well as fishing and natural mortality. Tagging studies mark and identify cohorts of animals, thus immigration and recruitment do not affect estimation of mortality rates. The effects of molting need to be eliminated so that a decline in legal-sized lobster abundance relates spe-

Received June 28, 2000. Accepted August 28, 2001. Published on the NRC Research Press Web site at http://cjfas.nrc.ca on December 19, 2001.

$\mathrm{J} 15842$

S.D. Frusher. ${ }^{1}$ Tasmania Aquaculture and Fisheries Institute, University of Tasmania, G.P.O. Box 252-49, Hobart, Tasmania 7001, Australia.

J.M. Hoenig. Virginia Institute of Marine Science, College of William and Mary, P.O. Box 1346, Gloucester Point, VA 23062, U.S.A.

${ }^{1}$ Corresponding author (e-mail: stewart.frusher@utas.edu.au). 
Fig. 1. Map of Australia showing northwest Tasmania and study site.

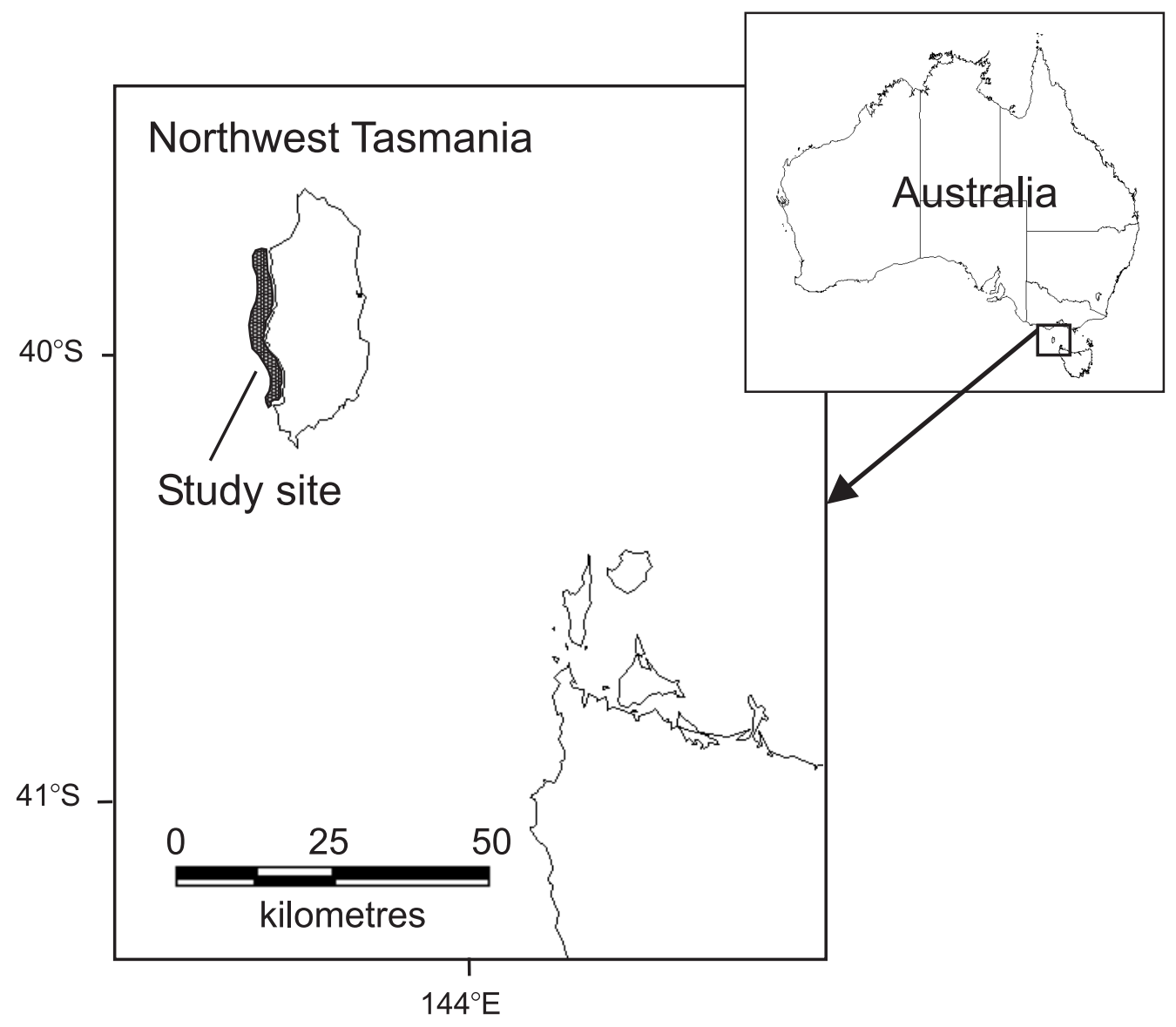

cifically to those lobsters that were present at the start of the fishery.

Tagging studies undertaken from 1992 to 1995 had the objective of obtaining growth and movement data. Despite this, we found that the data could be used to develop and evaluate tagging models for estimating mortality rates. This paper evaluates these models.

Brownie et al. (1985) presented a number of models for estimating year-specific survival and tag recovery rates from multiyear tagging studies. Kleiber et al. (1987) expressed tag return data in terms of tag reporting rate and fishing and natural mortality. Hoenig et al. (1998) reparameterized the multiyear tagging models of Brownie et al. (1985) in a very general formulation that expresses survival in terms of instantaneous rates of fishing and natural mortality. The recovery rate parameter was expressed as a product of three factors: the exploitation rate, tag reporting rate, and a parameter that includes tag loss and tag-induced mortality. The exploitation rate can be expressed as a function of the fishing and natural mortality rates. Tag loss and tag-induced mortality can be determined from separate studies, such as aquarium and double-tagging trials. Although tag reporting rate can theoretically be estimated from the models, Hoenig et al. (1998) found that tag reporting rate estimates were unreliable unless there are many years of tagging with a wide range of fishing mortality rates.

Hearn et al. (1998) described a model that used tagging data from tagging twice per year to estimate fishing and natu- ral mortality. They were also able to estimate tag reporting rate. Their model has a fishing period where both fishing and natural mortality affect survival and a closed period of the year where only natural mortality affects survival. Tagging is undertaken before and after the fishing year. We combined aspects of the models described by Hearn et al. (1998) and Hoenig et al. (1998) to describe the dynamics of the lobster stock from the King Island area in northwest Tasmania.

\section{Materials and methods}

\section{Study design}

From 1992 to 1995 , lobsters were tagged during research cruises off the coast of northwest Tasmania on the commercial fishing grounds (Fig. 1). The same tagging sites were visited on all cruises. Lobsters were tagged immediately upon capture and released at the site of capture. Lobsters were tagged with individually numbered T-bar tags (Hallprint T-bar anchor tag; TBA1, Hallprint Pty. Ltd., 27 Jacobsen Crescent, Holden Hill, South Australia 5088, Australia). Lobsters were tagged in February, May, and September from September 1992 to May 1995.

Tagging sites were situated within the main fishing grounds. Pearn (1994) found that legal-sized lobsters were primarily recaptured in the location of release. All of the available habitat for $J$. edwardsii is routinely fished each season.

Notices requesting return of tags were posted to all fishers and processors known to process Tasmanian rock lobsters. To encourage participation a tag lottery was established. Each correctly completed tag return represented an entry into the lottery. Advertising of the tagging project was undertaken by regular articles in the 


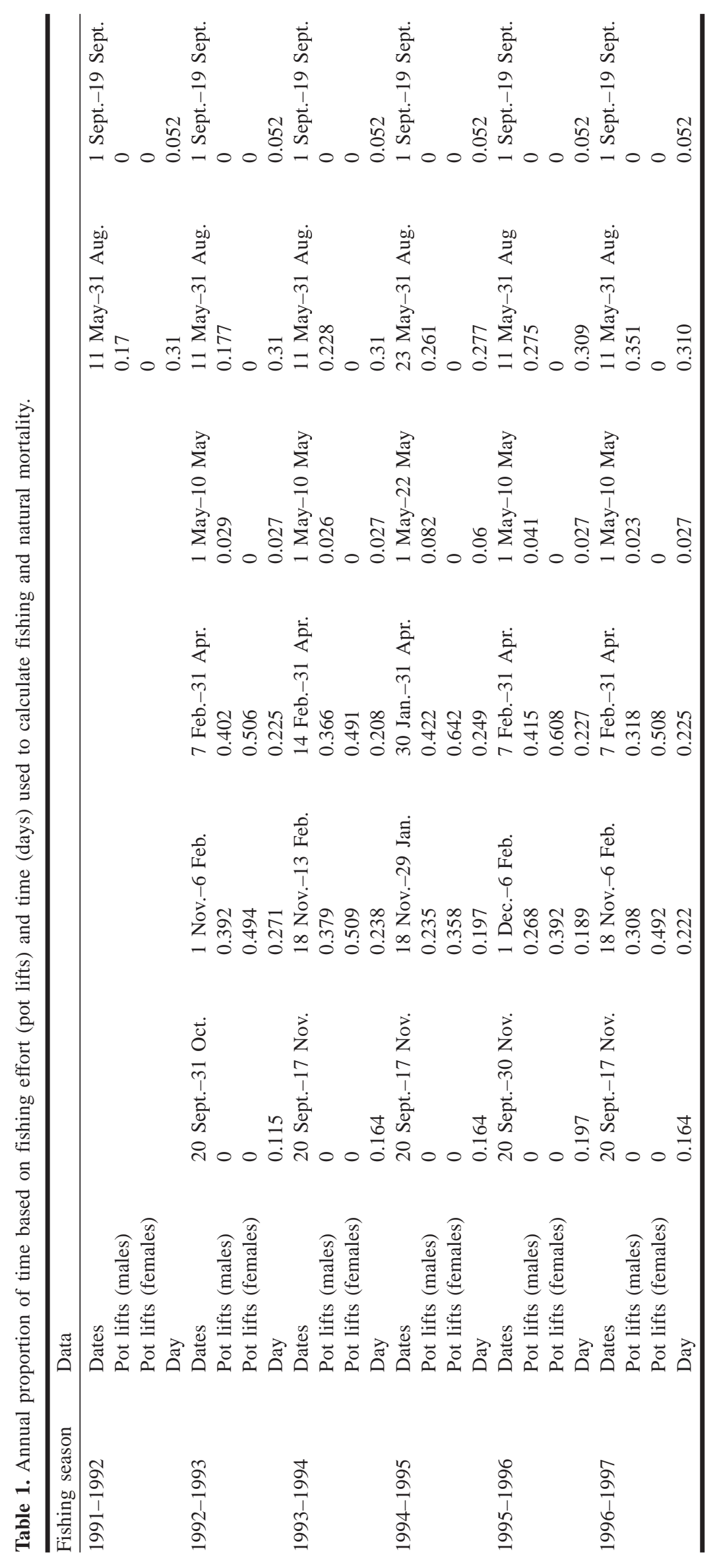


Table 2. Terminology used to describe models.

\begin{tabular}{ll}
\hline Model code & Description \\
\hline $2 \times$ & Two tagging events per year (September and May) \\
$3 \times$ & Three tagging events per year (September, February, and May) \\
$\mathrm{S}$ & Fs estimated for separate sexes \\
$\mathrm{Ct}$ & Fs estimated for sexes combined based on lengths of time of fishing periods \\
$\mathrm{Ce}$ & Fs estimated for sexes combined based on amount of fishing effort in each sex's fishing period \\
$\mathrm{yA}$ & Fs estimated for each year of recaptures \\
$\mathrm{yC}$ & Fs estimated for all years combined (constant $F$ ) \\
\hline
\end{tabular}

fishing industry magazine (Fishing Today) and by regular oral presentations at the Tasmanian Rock Lobster Fishermen's Association meetings.

The Tasmanian rock lobster fishery opens in November for both males and females, although the exact date has varied slightly over the years from 1992 to 1995 . The female and male fishing periods close at the end of April and August, respectively, of the following year. Although female lobsters are caught from May to the end of the male fishing period in August, it is mandatory that they be returned to the sea. These female lobsters are rarely checked for tags and any that were reported have not been included in the analysis. During the recapture periods, there were no reports of tagged female lobsters that died because of the fishing activity (e.g., from predation by an octopus in the trap). For application of the Hearn et al. (1998) method, September was a preseason tagging event and May was a postseason tagging event for females. Models developed in this paper utilize data on both sexes and two or three tagging events.

\section{Development of statistical models for tagging data}

To model the tag returns within a year, we need to have the fishing and natural mortality rates reflect what happens in each period between tagging events. Hoenig et al. (1998) derived formulae where fishing and natural mortality are prorated against fishing effort and the length of time since tagging, respectively. These formulae and their adaptation to our data are presented in Appendix A.

\section{Parameter estimability and methods for fitting models}

There is no universally applicable method for determining estimability of parameters. However, for these models the estimability can easily be demonstrated using the method of moments (Appendix B).

In practice, the models are fitted by the method of maximum likelihood. The recoveries over time from each cohort of tagged animals constitute an observation from a multinomial distribution. The cohorts are considered independent. Thus, the likelihood for the data is a product of the multinomials.

Models were fitted using the program SURVIV (White 1983). Because of the large number of parameters to be estimated, tag reporting rate $\lambda$ and natural mortality rate $M$ were held constant over all years. Program SURVIV was developed to estimate survival rates and these estimates are constrained to be between 0 and 1. As the instantaneous mortality rates can be larger than 1, the fishing mortality parameters were transformed:

$$
\hat{F}=-\ln \hat{T}
$$

where $\hat{F}$ is the instantaneous fishing mortality estimate and $\hat{T}$ is the exponential of the negative of the fishing mortality estimate. Thus, we estimated $T$ and then obtained the estimate of $F$ from $\hat{T}$. By the invariance principle of maximum likelihood estimation, the resulting estimate of $F$ is a maximum likelihood estimate.

Standard errors (SE) of the fishing mortalities were obtained from the SEs of the estimated $T$ parameters by application of the delta method (Seber 1982). Thus,

$$
\operatorname{SE}(\hat{F})=\frac{\operatorname{SE}(\hat{T})}{\hat{T}}
$$

\section{Models tested}

The available data allowed for the testing of 12 models. These models were based on two tagging strategies: tagging twice $(2 \times$, in September and May) or three times $(3 \times$, in September, February, and May) per year. For each of these strategies, models were established to determine fishing mortalities for each sex separately or for sexes combined. For the latter, fishing mortality for each sex was specified as being proportional to the length of the fishing period for that sex (the length of the fishing period for females being $60 \%$ as long as the fishing period for males.) Alternatively, fishing mortality was specified as being proportional to the amount of fishing effort in the open fishing period for each sex (Table 1). Combining sexes is considered appropriate, as both male and female lobsters are attracted to fishing pots. Fishers consider both sexes equally catchable with the exception of periods when either sex is molting.

Each of these models estimated fishing mortality annually. However, it is possible to constrain the fishing mortality to be constant over the years, and models were also evaluated with $F$ held constant over time. Models were described using the descriptors in Table 2. For example, $2 x-\mathrm{Ct}-\mathrm{yA}$ refers to the model based on two tagging events with fishing mortality estimated annually for sexes combined based on length of fishing period.

\section{Model selection}

Initial model selection was based on parsimony. Burnham and Anderson (1998) describe parsimony as the concept that a model should be as simple as possible with respect to the model structure and number of parameters. Following the procedures of Burnham and Anderson (1998), we used Akaike's information criterion (AIC) to formally select models. This strategy compares the improvement in fit of models with increased numbers of parameters to the most parsimonious model. Only models with a substantial improvement in fit are considered more appropriate than the parsimonious model.

\section{Diagnostics for lack of fit}

Recently, R. Latour (VIMS, P.O. Box 1346, Gloucester Point, VA 23062, U.S.A., personal communication) suggested looking at residuals as a diagnostic tool for assessing tagging models. We analyzed the residuals of the selected model for patterns that would indicate the problems described by Latour.

\section{Results and discussion}

The number of legal-sized lobsters tagged in the survey periods ranged from 94 to 577 lobsters; the number of recaptures from the tagged cohorts ranged from 6 to 129 (Table 3). 


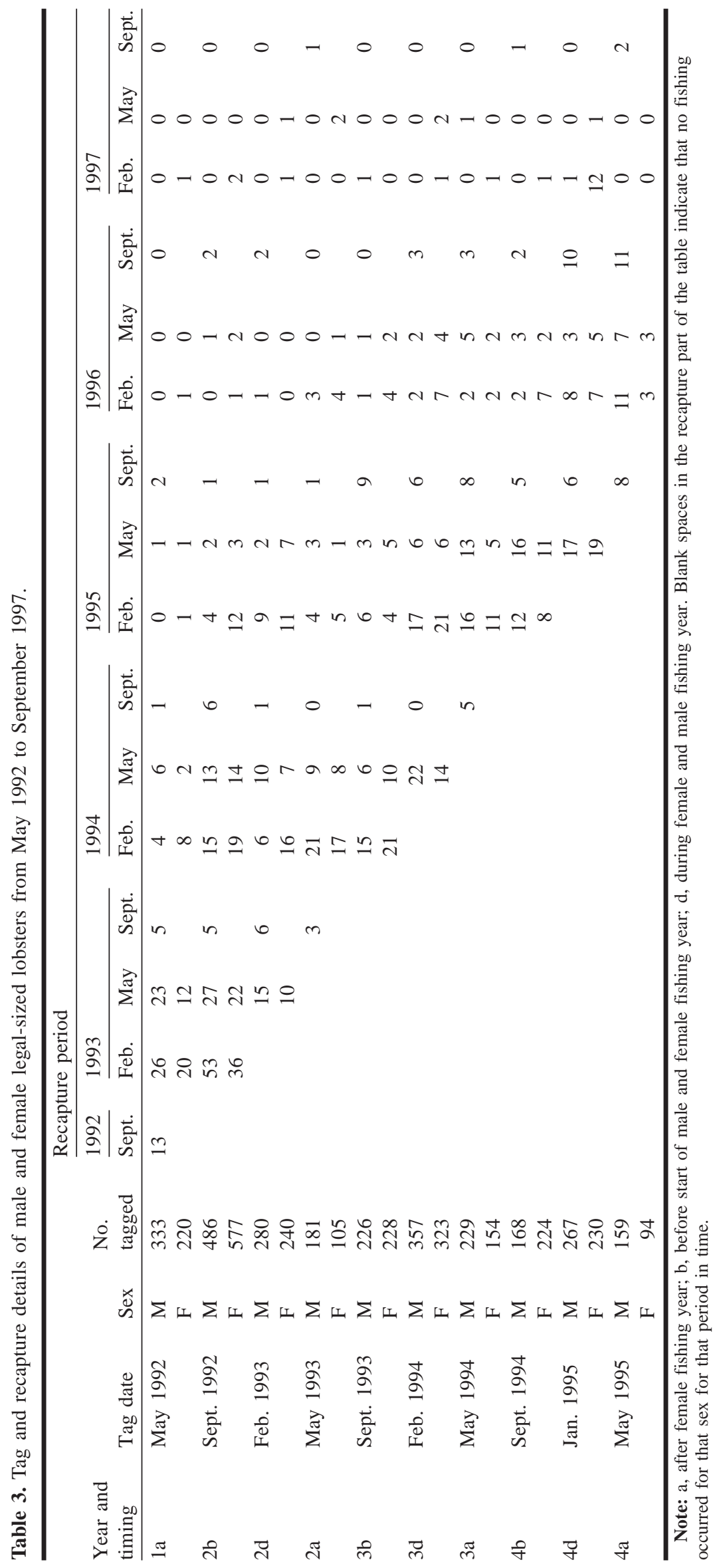


Table 4. Dispersion coefficients $(\hat{c}), \Delta$ QAIC values, AIC weights (wQAIC), and level of support for two groups of models based on two $(2 x)$ and three $(3 x)$ tagging events per year.

\begin{tabular}{lllllc}
\hline Group & Model & $\hat{c}$ & $\Delta$ QAIC & wQAIC & Support \\
\hline $3 \times$ & S-yA & 2.05 & 3.02 & 0.07 & 4.53 \\
& S-yC & 2.15 & 0.10 & 0.29 & 1.05 \\
& Ct-yA & 2.14 & 4.35 & 0.03 & 8.81 \\
& Ct-yC & 2.18 & 4.32 & 0.03 & 8.69 \\
& Ce-yA & 2.11 & 0.00 & 0.30 & 1.00 \\
$2 \times$ & Ce-yC & 2.15 & 0.19 & 0.27 & 1.10 \\
& S-yA & 1.92 & 4.12 & 0.06 & 7.84 \\
& S-yC & 2.41 & 5.57 & 0.03 & 16.23 \\
& Ct-yA & 1.95 & 0.00 & 0.43 & 1.00 \\
& Ct-yC & 2.20 & 3.08 & 0.09 & 4.67 \\
& Ce-yA & 1.96 & 0.52 & 0.33 & 1.30 \\
& Ce-yC & 2.20 & 3.90 & 0.06 & 7.06 \\
\hline
\end{tabular}

Note: A QAIC is quasi-likelihood adjustment of the AIC value to account for overdispersion of the data. A $\triangle \mathrm{QAIC}$ value is the difference between the QAIC value for a model and the smallest QAIC value for any model in the group (see Burnham and Anderson 1998 for further details). See Table 2 for model descriptors. Models with support values less than 2 are considered plausible models.

\section{Model selection}

Data for all models were found to be overdispersed and quasi-likelihood adjustments of the AIC values were undertaken (see Burnham and Anderson 1998) (Table 4).

Two groups of models used equivalent amounts of data and model selection within these groups was based on their AIC weights (Burnham and Anderson 1998) (Table 4). The $2 \times$ group was based on considering two tagging events per year (September and May) and the $3 \times$ group was based on three tagging events per year (September, February and May). In the $3 \times$ group, models $3 \times-\mathrm{Ce}-\mathrm{yA}, 3 \times-\mathrm{S}-\mathrm{yC}$, and $3 \times-\mathrm{Ce}-\mathrm{yC}$ had support values less than 2 , as had models $2 \times-\mathrm{Ct}-\mathrm{yA}$ and $2 \times-\mathrm{Ce}-\mathrm{yA}$ in the $2 \times$ group (Table 4 ). These models should be considered plausible models for the northwest Tasmanian tag recapture data.

Common to both groups was the $\mathrm{Ce}-\mathrm{yA}$ model, which estimates annual fishing mortalities with sexes combined based on effort. The other model supported in the $2 \times$ group was the model estimating annual fishing mortalities with sexes combined based on the duration of the fishing years. This is not surprising because when the February tagging event is eliminated, the fishing period for males is reduced from 3 (Nov.-Feb., Feb.-May, May-Aug.) to 2 (Nov.-May, May-Aug.) periods and from 2 (Nov.-Feb., Feb.-Apr.) to 1 (Nov.-Apr.) period for females (Table 1). Although a model based on separate sexes was given support in the $3 \times$ group, the addition of the extra parameter (sex effect) did not have a substantial improvement over the most parsimonious model and this model is not considered further.

In the $3 \times$ model group, fishing mortality estimates with sexes combined based on length of the fishing periods were poorly supported, indicating that the extra tagging period (February) split a period when fishing effort was disproportional to time. There are differences in effort between tagging periods, with the period between the second and third tagging surveys (Feb.-May) having the greatest effort ex-
Fig. 2. Comparison of fishing effort expended between September and February (open squares), February to May (solid squares) and May to September (solid circles) for the 1992-1993 to 1996-1997 fishing years. The horizontal line shows were the proportion of effort is equivalent to the proportion of time.

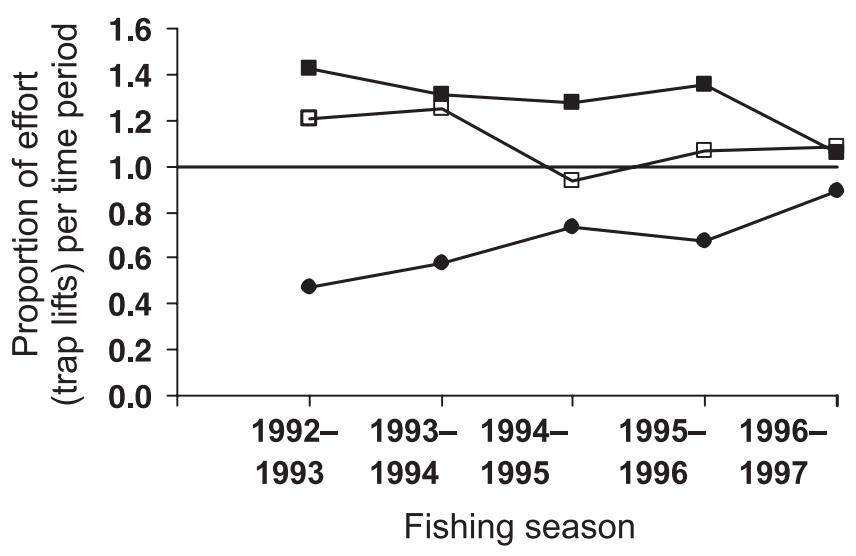

pended per unit of time (Fig. 2). In contrast, the period between the third and first tagging surveys of the following year (May-Sept.) had less effort per unit of time. Over the survey periods, the May to September period has shown a steady increase in the amount of effort expended per unit of time, which reflects the increase in price paid over time for lobster during this period (Frusher 1997). Effort is considered the most appropriate means of partitioning fishing mortalities within a fishing year.

The models producing annual estimates of fishing mortalities with fishing mortality within a year based on fishing effort were considered the most appropriate models for describing the dynamics of the lobster stocks in northwest Tasmania. As the $2 x-\mathrm{Ce}-\mathrm{yA}$ and $3 x-\mathrm{Ce}-\mathrm{yA}$ models used different amounts of data, model selection was based on the relative standard errors of the parameters being estimated. In all cases the model based on three tagging events per year had lower relative standard errors than the model based on two tagging events per year.

\section{Model fit}

The residuals from the fitted models (e.g., Table 5) display none of the symptoms of problems described by R. Latour (VIMS, P.O. Box 1346 Gloucester Point, VA 23062, U.S.A., personal communication) (i.e., row effects and diagonal effects). There is a preponderance of negative residuals, however, and some columns contain residuals predominantly of the same sign. Latour was unable to generate this kind of column pattern in his simulations though they specifically tried to produce this effect. The model considered here is more complex than the model of Hoenig et al. (1998), which was investigated by Latour (VIMS, P.O. Box 1346 Gloucester Point, VA 23062, U.S.A., unpublished data). Thus, there are potentially more ways that problems could occur. For example, if the residuals for females were of the opposite sign to those of males in a particular recovery year, it might suggest that the molting season for females was unusually early or late relative to molting of males in that year. This does not appear to be the case here. Like Latour, we are unable to suggest a mechanism that would 


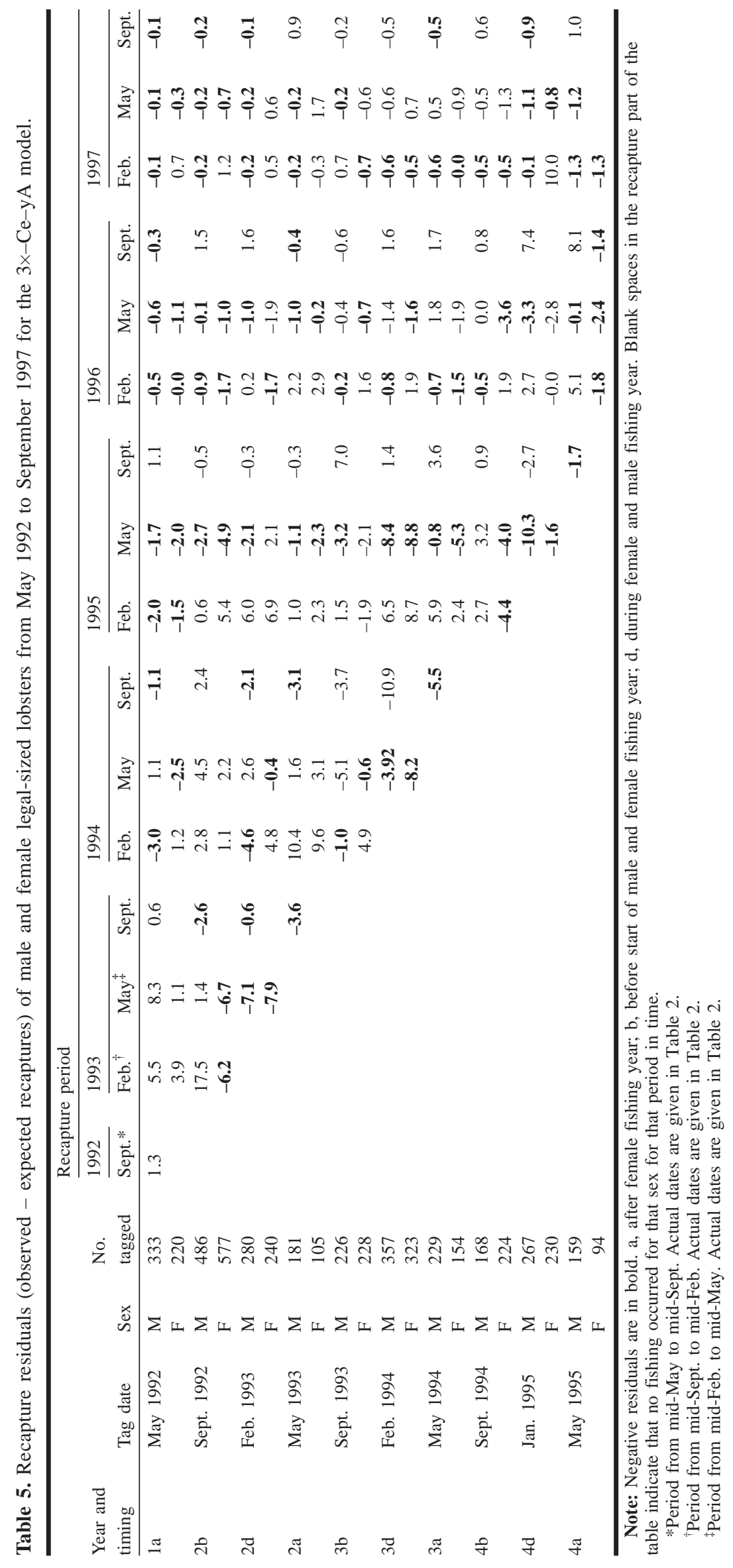


Fig. 3. Comparison of $(a)$ instantaneous fishing mortality rate, $(b)$ tag reporting rate, and $(c)$ instantaneous natural mortality rate estimates from $2 \times$ and $3 \times$ models. Bars give estimated parameters with one standard error. Connected dots show relative standard error (RSE). Meaningful RSE estimates could not be obtained for natural mortality estimates because they approached zero.

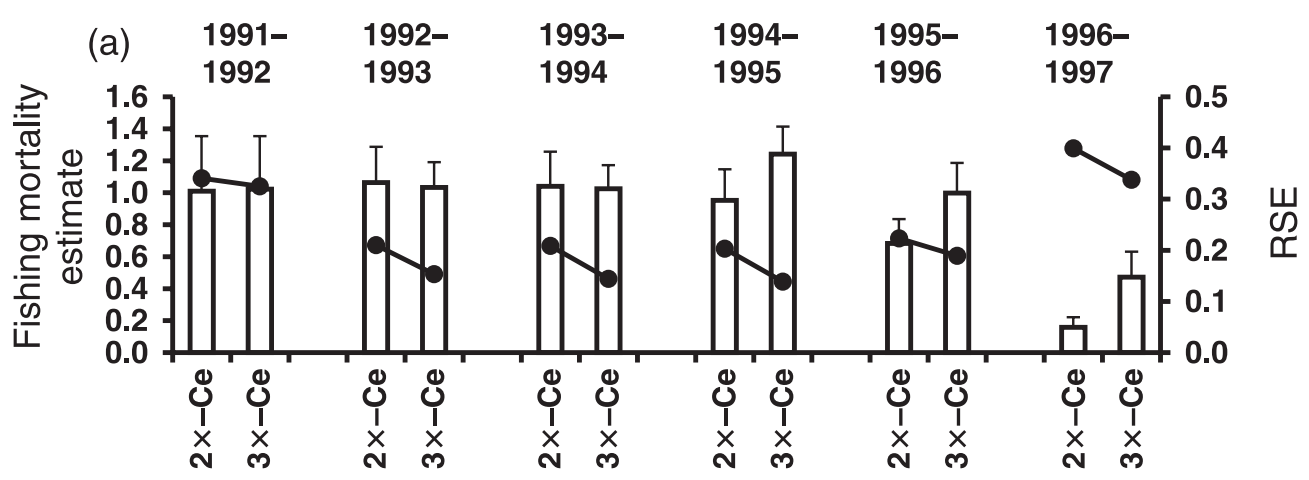

(b)

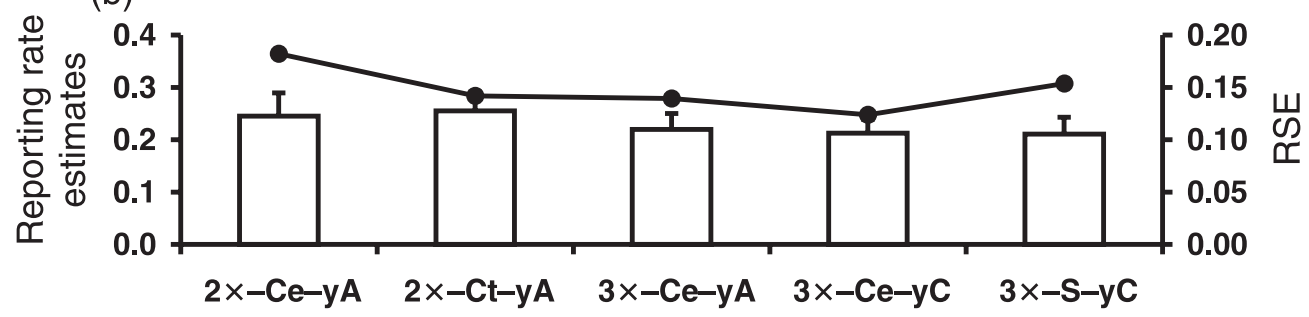

(c)

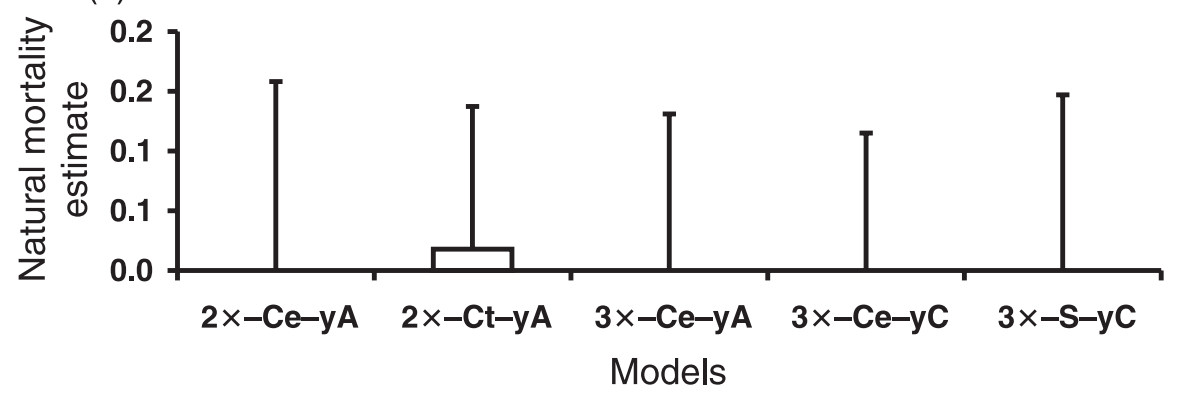

generate a column effect. We suggest this may be an important area for research.

A reviewer of the manuscript suggested that certain cells of the recovery matrix with large residuals might be exerting an undue influence on the estimates. We examined the table of residuals (Table 5) for evidence of a problem and tried fitting the model after deleting cells for which the residuals were large $(>5)$. After deleting these cells, there were only minor changes in the parameter estimates. Exploitation rates for the 1991-1992 to 1993-1994 fishing years increased from $64 \%$ to $67 \%$ and declined for the $1994-1995$ (71\% to 65\%), $1995-1996$ (63\% to 52\%), and 1996-1997 (37\% to $18 \%$ ) fishing years. The larger differences for the last two fishing years are considered to be due to the low number of tags returned after tagging ceased in May 1995, as previously described. Tag reporting rate increased from $22 \%$ to $24 \%$ and natural mortality remained at zero. The precision of all estimates decreased after the cells with large residuals were removed and there was no change in the column effects of the residuals.

We conclude that although there are some patterns in the residuals, the cause is unclear, as is how the unidentified problem might bias the results. However, as discussed below, the overall results are consistent with those results obtained from the assessment model of Punt and Kennedy (1997), so there is reason to believe that the model has provided reasonable results.

\section{Fishing mortality}

Tagging during this study commenced part way through the 1991-1992 fishing year in May 1992. The female component of this fishing year had already closed and thus fishing mortality estimates are based on males for 1991-1992. Only 17\% of the fishing effort for the 1991-1992 fishing year was expended between May and September 1992, thus male fishing mortality for this period is based on recaptures from limited effort.

Comparison of the relative standard error $(\mathrm{RSE}=$ SE/estimate) of the supported models, which estimated annual fishing mortalities, showed that the $3 \times-C e$ model provided the most precise estimates for all fishing years (Fig. 3a).

The fishing mortality estimates for the 1991-1992 to 1993-1994 fishing years were similar. Fishing mortality estimates for 1994-1995 to 1996-1997 were greater for the $3 \times$ than $2 \times$ models. The $2 \times$ model showed a decline in fishing 
Fig. 4. Comparison of annual fishing effort and fishing mortality estimates from $(a)$ the $3 \times$ model and $(b)$ the $2 \times$ model based on time (open bars) and effort (solid bars). Histogram provides estimated fishing mortality with one standard error. Connected dots show effort.

(a)

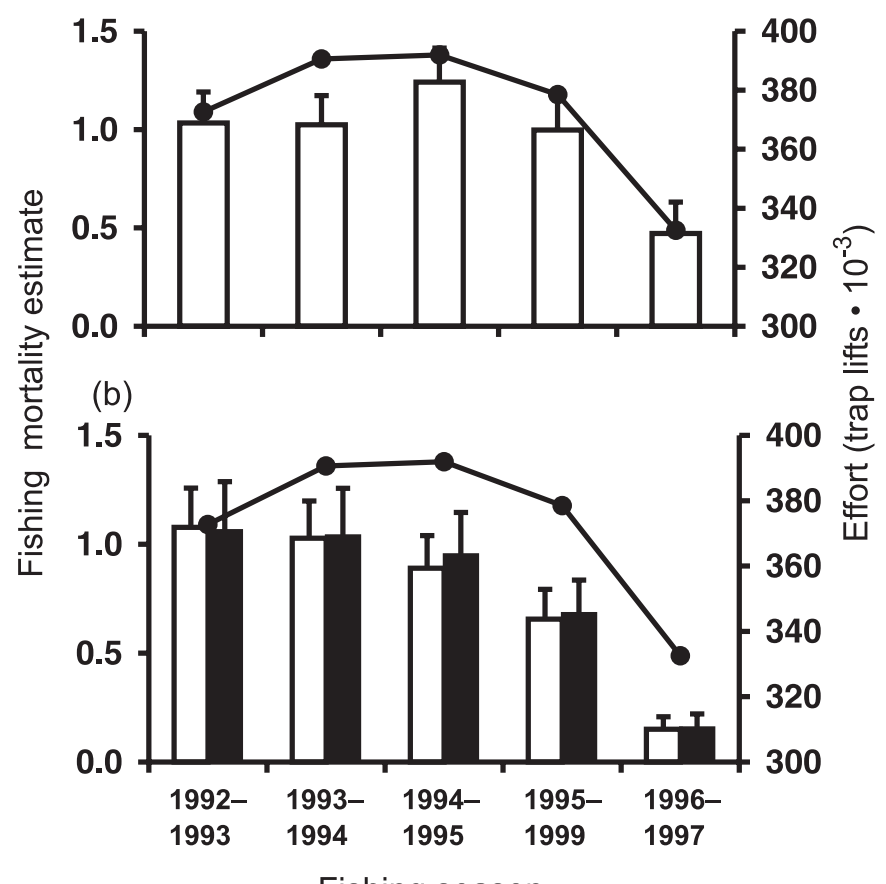

Fishing season

Table 6. Instantaneous fishing mortality rates $\left(F\right.$, year $\left.^{-1}\right)$, exploitation rates $\left(u=1-\mathrm{e}^{-F}\right)$, annual catches $(C)$ and estimated biomass $(B=C / u)$ from the $3 \times-\mathrm{Ce}-\mathrm{yA}$ model.

\begin{tabular}{lllll}
\hline $\begin{array}{l}\text { Fishing season } \\
\text { (Nov.-Aug.) }\end{array}$ & $F$ & $u$ & $C$ (tonnes) & $B$ (tonnes) \\
\hline $1991-1992$ & 1.02 & 0.64 & 431.7 & 674.5 \\
$1992-1993$ & 1.03 & 0.64 & 364.8 & 566.5 \\
$1993-1994$ & 1.03 & 0.64 & 392.2 & 611.9 \\
$1994-1995$ & 1.24 & 0.71 & 362.1 & 509.2 \\
$1995-1996$ & 1.00 & 0.63 & 360.4 & 571.1 \\
$1996-1997$ & 0.47 & 0.38 & 325.8 & 866.6 \\
\hline
\end{tabular}

mortality estimates from 1993-1994, whereas this was only apparent in the 1996-1997 fishing year for the $3 \times$ model.

Fishing effort is often used as a measure of relative fishing mortality. Fishing effort for the region where tagging was undertaken is available from 1992 onwards. Trends in fishing effort are comparable to the fishing mortality estimates from both models, although the $3 \times$ model appears to be a better relative comparison (Fig. 4). Only in the 19961997 fishing year was the trend in effort substantially differentfrom the trend in annual fishing mortality estimates, whereas the last two fishing years diverge from the effort trend in the $2 \times$ model.

The precision (equivalent to RSE) of the estimates for the most recent years declines with the 1996-1997 estimates being approximately half as precise as the earlier fishing year estimates (with the exception of the 1991-1992 fishing year, when the estimate was based on $17 \%$ of the fishing effort).
The declining precision for the last fishing years is likely to be due to the low number of tags returned during this period as tagging ceased in May 1995 when exploitation rates remained high. In the fishing year (1995-1996) immediately after tagging ceased, $60 \%$ of the tagging event recapture period strata had 2 or fewer returns. In the 1996-1997 fishing year, this increased to $98 \%$, with $66 \%$ having zero returns (Table 3).

The most precise estimates were obtained from the $3 \times-$ $\mathrm{Ce}-\mathrm{yA}$ model. These estimates are high with annual harvesting of between $60 \%$ and $70 \%$ of the legal-sized biomass for all fishing years except the last (Table 6). Although high, these estimates are similar to those found by Frusher et al. (1998) for other regions of Tasmania and have similar trends to biomass estimates obtained from a rock lobster assessment model (Punt and Kennedy 1997), with the exception of the final year. The low fishing mortality estimate for the final year is considered to be due to the low expected rate of tag returns, as discussed earlier.

High exploitation rates in the Tasmanian rock lobster fishery are not unexpected, as Frusher (1997) reports legal-sized biomass to be around $6 \%$ of the virgin legal-sized biomass. Additionally, the majority of the legal-sized biomass is composed of recent recruits (Frusher 1997).

\section{Tag reporting rate}

In the models tested, tag reporting rate was held constant over all years. Although fishers' behavior with respect to reporting tags can vary between years, there were no major fishery policy changes during the period of surveys that might have altered fishers' behaviour.

Reporting rate and its relative precision showed little variation between models and was estimated reasonably precisely (Fig. 3b). S.D. Frusher (personal observation) found no tag loss or tag-induced mortality from over 100 lobsters held in aquaria. Treble (1996) found tag loss to be approximately $3 \%$ annually for T-bar tags used in the same species. Although these components of the reporting rate parameter are considered to be low, reporting rate estimates were low ( 0.20 to 0.23$)$, indicating that fisher cooperation in looking for tags and subsequently reporting tags was poor.

\section{Natural mortality}

Natural mortality was also held constant over all years. Natural mortality estimates were very close to zero or very low, ranging from $0-0.018 \cdot$ year $^{-1}$ (Fig. 3c). However, the standard errors were relatively large. This indicates that the models tested had trouble estimating this parameter. This may be owing to the relatively short period of time that natural mortality was responsible for total mortality (i.e., when the fishery was closed). In the Tasmanian fishery, the female fishing period is closed for approximately half the year. Hearn et al. (1998) expected that their method would work well in a pulse fishery (i.e., when the fishery is open for such a short time that natural mortality can be considered to be negligible during the fishing period) or when applied to a fishery with a short fishing period (i.e., less than four months).

A concern with the very low estimates of $M$ is that they could be highly correlated with tag reporting rate estimates. However, the covariance matrix obtained from SURVIV (White 1983) indicates that this is not the case. We con- 
firmed this by rerunning the model with $M$ fixed at $0.1,0.15$, and 0.2 . These resulted in an increase in tag reporting rate of $11 \%, 18 \%$, and $25 \%$, respectively, and a decrease in $F \mathrm{~s}$ by $10 \%, 15 \%$, and $20 \%$, respectively, for the first three fishing seasons. These variations were smaller for the later years of the study.

Natural mortality has proved to be very difficult to estimate in lobster stocks. Kennedy (1992) tried to estimate natural mortality of female lobsters from long-term (>15 years) recaptures. Although no definitive estimate could be made from the data, he considered natural mortality for the southern Tasmanian females to be 0.1 or less. Hearn et al. (1998) found that their method produced accurate estimates of $M$ when $M$ was high, although large numbers of animals were required to be tagged $(>1000)$ when fishing mortality was low and reporting rate was $50 \%$ or less.

Low tag reporting rates and high fishing mortality rates would make a low natural mortality estimate difficult from tag recapture data. The high fishing mortality will result in few tags being available after one period of fishing and, combined with low tag reporting rate, few tags will be available to estimate $M$. Frusher and Hoenig (2001) found that improved precision in the estimates of $M$ was best achieved by either improving the tag reporting rate or increasing the duration of the tagging events from three to six fishing seasons.

The large standard errors of the natural mortality estimate also indicate that natural mortality is difficult to determine. However, the natural mortality estimates from all models tested were low, which supports the inferences made by Kennedy (1992).

This is the first time these models have been applied to a real situation and the results are encouraging. Fishing mortality estimates had reasonable estimated precision, and the trends matched results from other methods. Although it is possible to estimate fishing mortality in years after the cessation of tagging, this does not appear to work well when fishing mortality is high owing to the tags being "fished out". It is well known that most methods that produce estimates of fishing and natural mortality tend to produce highly correlated estimates. But, the estimated correlations in this study were modest.

This analysis is also the first time that a detailed model with multiple tagging events within a fishing year has been tested. The $3 \times$ model with fishing mortality apportioned by fishing effort and with sexes combined appears to be appropriate for estimating fishing mortality in the northern Tasmanian rock lobster fishery. The precision of natural mortality estimates was low, however, all models indicated that natural mortality was low.

Despite the poor reporting rate, relatively precise estimates of fishing mortality could still be achieved. This is important for the northern Tasmanian fishery, where attempts at estimating fishing mortality rate using other methods have been compromised by the frequent molts and extended molting period of the lobsters.

\section{Acknowledgments}

Mr. Steve Bishop, owner and operator of the fishing vessel Lady Suzanne was contracted to undertake the surveys.
His knowledge and experience in fishing the northwestern Tasmanian rock lobster fishing grounds was invaluable. $\mathrm{Mr}$. Jac Gibson, Senior Technical Officer, provided valuable technical support. Mr. Dan Hepworth's computing skills are gratefully acknowledged.

\section{References}

Brownie, C., Anderson, D.R., Burnham, K.P., and Robson, D.S. 1985. Statistical inference from band recovery data-a handbook. 2nd ed. U.S. Fish Wildl. Serv. Resour. Publ. No. 156.

Burnham, K.P., and Anderson, D.R. 1998. Model selection and inference. A practical information-theoretic approach. SpringerVerlag, New York.

Delury, D.B. 1947. On the estimation of biological populations. Biometrics, 3: 145-167.

Frusher, S.D. 1997. Stock assessment report: rock lobster. Government of Tasmania, Australia, Internal Report No. 35. Tasmanian Department of Primary Industry and Fisheries, Hobart.

Frusher, S.D., and Hoenig, J.M. 2001. Strategies for improving the precision of fishing and natural mortality estimates from multi-year tagging models: a case study. Mar. Freshw. Res. 52: 1649-1655.

Frusher, S.D., Kennedy, R.B., and Gibson, I.D. 1997. Precision of exploitation rate estimates in the Tasmanian rock lobster fishery based on change-in-ratio techniques. Mar. Freshw. Res. 48: 1069-1074.

Frusher, S.D., Kennedy, R.B., and Gibson, I.D. 1998. Preliminary estimates of exploitation rates in the Tasmanian rock lobster (Jasus edwardsii) fishery using the change-in-ratio and index removal techniques with tag-recapture data. In Proceedings of the North Pacific symposium on invertebrate stock assessment and management, 6-10 March 1995, Nanaimo, B.C., Canada. Edited by G.S. Jamieson and A. Campbell. Can. Spec. Publ. Fish. Aquat. Sci. No. 125. pp. 63-71.

Hearn, W.S., Pollock, K.H., and Brooks, E.N. 1998. Pre- and postseason tagging models: estimation of reporting rate and fishing and natural mortality rates. Can. J. Fish. Aquat. Sci. 55: 199-205.

Hoenig, J.M., and Pollock, K.H. 1998. Index-removal methods. In Encyclopedia of Statistical Sciences Update. Vol. 2. Edited by S. Kotz, C.B. Read, and D.L. Banks. John Wiley and Sons, Inc., New York. pp. 342-346.

Hoenig, J.M., Barrowman, N.J., Hearn, W.S., and Pollock, K.H. 1998. Multiyear tagging studies incorporating fishing effort data. Can. J. Fish. Aquat. Sci. 55: 1466-1465.

Kennedy, R.B. 1992. The biology and fishery for the southern rock lobster Jasus edwardsii in Tasmania: a confidential working document summarizing Tasmanian fishery and the fishery related information which is available within Tasmania. Tasmanian Dept. of Prim. Ind., and Fisheries, Taroona.

Kleiber, P., Argue, A.W., and Kearney, R.E. 1987. Assessment of pacific skipjack tuna (Katsuwonus pelamis) resources by estimating standing stock and components of population turnover from tagging data. Can. J. Fish. Aquat. Sci. 44: 1122-1134.

Leslie, P.H., and Davis, D.H.S. 1939. An attempt to measure the absolute number of rats on a given area. J. Anim. Ecol. 8: 94-113.

Pearn, R. 1994. Rock lobster tagging shows movement occurs. Fishing Today, 7(5): 27-29.

Pollock, K.H., and Hoenig, J.M. 1998. Change-in-ratio estimators. In Encyclopedia of statistical sciences update. Vol. 2. Edited by S. Kotz, C.B. Read, and D.L. Banks. John Wiley and Sons, Inc., New York. pp. 109-112.

Punt, A.E., and Kennedy, R.B. 1997. Population modeling of the Tasmanian rock lobster, Jasus edwardsii, resources. Mar. Freshw. Res. 48: 967-980. 
Seber, G.A.F. 1982. The estimation of animal abundance and related parameters. 2nd ed. Griffin, London.

Treble, R.J. 1996. The southern rock lobster (Jasus edwardsii): fisheries biology and abundance estimation. Ph.D. dissertation. University of Melbourne, Australia.
White, G.C. 1983. Numerical estimation of survival rates from bandrecovery and biotelemetry data. J. Wildl. Manag. 47: 716-728.

\section{Appendix A. Derivation of exploitation rate in terms of natural and fishing mortality components and examples of application to a model using three tagging periods.}

\section{Notation}

$\lambda$ a composite parameter that represents the joint probability of three events: (i) the probability that a tag will be found and reported to the fisheries biologist, given that the tagged lobster has been harvested; (ii) the probability that a tagged lobsters does not die from the tagging process; and (iii) the probability that a tag is not shed immediately. $\lambda$ is assumed to be constant over time.

$F_{i}$ instantaneous fishing mortality rate in year $i$.

$F_{\mathrm{m} k i}$ instantaneous male fishing mortality in period $k$ of year $i$.

$F_{\mathrm{f} k i}$ instantaneous female fishing mortality in period $k$ of year $i$.

$M$ instantaneous natural mortality rate. $M$ is assumed to be constant over time and equal for both sexes.

$N_{\text {mhi }}$ number of male lobsters tagged and released at time $h$ of year $i$.

$N_{\mathrm{f} h i}$ number of female lobsters tagged and released at time $h$ of year $i$.

$\varepsilon_{i h}$ fraction of the annual fishing effort expended in period $h$ of year $i$.

$\Delta t_{h}$ length of the $h$ th period of the year.

$u_{i}\left(F_{i}, M\right)$ exploitation rate in year $i$. For convenience, this will be abbreviated to $u_{i}$ when clarity is not affected.

$R_{h i j k}$ number of recaptures of animals tagged in year $i$ at time $h$ and recaptured in year $j$ during period $k$.

$E\left[R_{h i j k}\right]$ expected value of $R_{h i j k}$.

Let the year be divided into $K=3$ periods. The exploitation rate in year $i$ can be expressed as

$$
u_{i}\left(F_{i}, M\right)=\sum_{k=1}^{K=3} a_{i k} b_{i k} c_{i k}
$$

Here, $a_{i k}$ is the fraction of the population surviving to the beginning of period $k$, with $a_{i 1}=1$ and

$$
a_{i k}=\exp \left(-M \sum_{h=1}^{k-1} \Delta t_{h}-F_{i} \sum_{h=1}^{k-1} \varepsilon_{i h}\right), k>1
$$

The $a_{i k}$ term prorates the natural mortality according to how much of the year has elapsed since tagging, and prorates the annual fishing mortality according to how much of the fishing effort has occurred up to the start of the $k$ th period. The $b_{i k}$ term is the fraction dying in period $k$

$$
b_{i k}=1-\exp \left(-M \Delta t_{k}-F_{i} \varepsilon_{i k}\right)
$$

and $c_{i k}$ is the fraction of the deaths in period $k$ owing to fishing

$$
c_{i k}=\frac{F_{i} \varepsilon_{i k}}{F_{i} \varepsilon_{i k}+M \Delta t_{k}}
$$

The following example is based on female lobsters in northwest Tasmania and partitions a year based on fishing periods and tagging events (Table A1). The tagging events are before $(B)$, during $(D)$, and after $(A)$ the fishing year. Fishing periods divide the year into before $(b)$, during $(d 1$ and $d 2)$, and after $(a 1$ and $a 2)$ the fishing year. The portions of effort and time are obtained from Table 1. Because recaptures are dependent on the fishery, recaptures are only obtained in periods $d 1$ and $d 2$.

The expected recoveries in the first portion of the fishing year $(d 1)$ in year 1 from tagging before the fishing year $(B)$ in year 1 is

$$
E\left[R_{1 B 1 d 1}\right]=\lambda N_{1 B} \exp (-0.115 M)\left(1-\exp \left(-0.494 F_{1}-0.271 M\right)\right)\left(\frac{0.494 F_{1}}{0.494 F_{1}+0.271 M}\right)
$$

where $N_{1 B}$ is the number of lobsters tagged at time $B, \exp (-0.115 M)$ is the number of lobsters that have survived period $b$ (of length 0.115 years), $\left(1-\exp \left(-0.494 F_{1}-0.271 M\right)\right)$ is the number of lobsters dying in period $d 1$, and $\left(\frac{0.494 F_{1}}{0.494 F_{1}+0.271 M}\right)$ is the proportion of lobsters dying in period $d 1$ from fishing. 
The expected recoveries in the second portion of the fishing year $(d 2)$ in year 1 from tagging before the fishing year $(B)$ in year 1 is

$$
E\left[R_{1 B 1 d 2}\right]=\lambda N_{1 B} \exp \left(-0.386 M-0.496 F_{1}\right)\left(1-\exp \left(-0.506 F_{1}-0.225 M\right)\right)\left(\frac{0.506 F_{1}}{0.506 F_{1}+0.225 M}\right)
$$

where $\exp \left(-0.386 M-0.496 F_{1}\right)$ is the number of lobsters that have survived prior to the start of period $d 2$ (i.e., survived period $b$ and $d 1),\left(1-\exp \left(-0.506 F_{1}-0.225 M\right)\right.$ is the number of lobsters dying in period $d 2$, and $\left(\frac{0.506 F_{1}}{0.506 F_{1}+0.225 M}\right)$ is the proportion of lobsters dying in period $d 2$ from fishing.

From the second tagging event $(D)$ in year 1 there would only be recaptures in year 1 from period $d 2$. The expected recovery is

$$
E\left[R_{1 D 1 d 2}\right]=\lambda N_{1 D}\left(1-\exp \left(-0.506 F_{1}-0.225 M\right)\right)\left(\frac{0.506 F_{1}}{0.506 F_{1}+0.225 M}\right)
$$

Note that there is no term for lobsters surviving prior to exploitation of the fishery as tagging commenced within the fishing year. There are no recoveries in year 1 from tagging after the fishing year $(A)$. In year 2 there would be expected recoveries from each of the tagging events in year 1 and, depending on the time of tagging, from some tagging events in year 2 .

The expected recoveries in period $d 1$ of year 2 from tagging events $B, D$, and $A$ of year 1 and tagging event $B$ of year 2 are $E\left[R_{1 B 2 d 1}\right], E\left[R_{1 D 2 d 1}\right], E\left[R_{1 A 2 d 1}\right]$, and $E\left[R_{2 B 2 d 1}\right]$, respectively, and are as follows:

$$
\begin{aligned}
& E\left[R_{1 B 2 d 1}\right]=\lambda N_{1 B} \exp \left(-1.164 M-F_{1}\right)\left(1-\exp \left(-0.509 F_{2}-0.238 M\right)\right)\left(\frac{0.509 F_{2}}{0.509 F_{2}+0.238 M}\right) \\
& E\left[R_{1 D 2 d 1}\right]=\lambda N_{1 D} \exp \left(-0.778 M-0.506 F_{1}\right)\left(1-\exp \left(-0.509 F_{2}-0.238 M\right)\right)\left(\frac{0.509 F_{2}}{0.509 F_{2}+0.238 M}\right) \\
& E\left[R_{1 A 2 d 1}\right]=\lambda N_{1 A} \exp (-0.526 M)\left(1-\exp \left(-0.509 F_{2}-0.238 M\right)\right)\left(\frac{0.509 F_{2}}{0.509 F_{2}+0.238 M}\right) \\
& E\left[R_{2 B 2 d 1}\right]=\lambda N_{2 B} \exp (-0.164 M)\left(1-\exp \left(-0.509 F_{2}-0.238 M\right)\right)\left(\frac{0.509 F_{2}}{0.509 F_{2}+0.238 M}\right)
\end{aligned}
$$

\begin{tabular}{|c|c|c|c|c|c|c|c|c|c|}
\hline & & $B$ & $b$ & $d 1$ & $D$ & $d 2$ & $a 1$ & $A$ & $a 2$ \\
\hline Season & Apportionment & $\begin{array}{l}\text { Tag } \\
\text { (Sept.) }\end{array}$ & $\begin{array}{l}\text { Fishing closed } \\
\text { (Sept.-Nov.) }\end{array}$ & $\begin{array}{l}\text { Fishing open } \\
\text { (Nov.-Feb.) }\end{array}$ & $\begin{array}{l}\text { Tag } \\
\text { (Feb.) }\end{array}$ & $\begin{array}{l}\text { Fishing open } \\
\text { (Feb.-Apr.) }\end{array}$ & $\begin{array}{l}\text { Fishing closed } \\
\text { (May) }\end{array}$ & $\begin{array}{l}\text { Tag } \\
\text { (May) }\end{array}$ & $\begin{array}{l}\text { Fishing closed } \\
\text { (May-Sept.) }\end{array}$ \\
\hline \multirow[t]{2}{*}{ 1992-1993 } & Effort & & 0 & 0.494 & & 0.506 & 0 & & 0 \\
\hline & Time & & 0.115 & 0.271 & & 0.225 & 0.027 & & 0.362 \\
\hline \multirow[t]{2}{*}{ 1993-1994 } & Effort & & 0 & 0.509 & & 0.491 & 0 & & 0 \\
\hline & Time & & 0.164 & 0.238 & & 0.208 & 0.027 & & 0.362 \\
\hline
\end{tabular}

Table A1. Terminology of fishing and tagging periods used in the text and example of apportionment of effort and time for two fishing years.

\section{Appendix B. Parameter estimability.}

In the example in Appendix $\mathrm{A}$, an estimate of $M$ can be obtained by dividing $E\left[R_{1 A 2 d 1}\right]$ by $E\left[R_{2 B 2 d 1}\right]$, which yields $\frac{N_{1 A} \exp (-0.526 M)}{N_{2 B} \exp (-0.164 M)}$ and can be equated with the observed ratio of recaptures $R_{1 A 2 d 1} / R_{2 B 2 d 1}$. This is easily solved to obtain an estimate of $M$. Similarly, dividing $E\left[R_{1 B 2 d 1}\right]$ by $E\left[R_{1 A 2 d 1}\right]$ or $E\left[R_{2 B 2 d 1}\right]$ yields $\frac{N_{1 B} \exp \left(-F_{1}-1.164 M\right)}{N_{1 A} \exp (-0.526 M)}=R_{1 B 2 d 1} / R_{1 A 2 d 1}$ or $\frac{N_{1 B} \exp \left(-F_{1}-1.164 M\right)}{N_{2 B} \exp (-0.164 M)}=R_{1 B 2 d 1} / R_{2 B 2 d 1}$, either of which is easily solved for $F_{1}$ once $M$ is known. Once $M$ and $F_{1}$ are known, $\lambda$ can be obtained from $\mathrm{E}\left[R_{1 B 1 d 1}\right]=R_{1 B 1 d 1}$. Similar logic can be used to establish the estimability of all of the parameters in the models considered here. 